\title{
STRESS PERCEPTION AMONG DENTISTS IN CROATIA
}

\author{
Andrija Ban', Ivan Galić2, Marin Vodanovic ${ }^{3}$ \\ 'Department of Paediatric Dentistry, University of Zagreb, Croatia \\ ${ }^{2}$ Department of Oral Surgery, School of Medicine, University of Split, Croatia \\ ${ }^{3}$ Department of Dental Anthropology, University of Zagreb, University Hospital Centre Zagreb, Croatia
}

\begin{abstract}
INTRODUCTION: Stress is currently ubiquitous in the modern world and dentists are very susceptible to stress. ОвJеCтIVEs: The aim of this study was to evaluate subjective perception of stress in dentists, confirm known correlations between stress and various factors, such as gender, age, socioeconomic level, work seniority, and specialization.

MATERIAL AND METHODS: The research was conducted through an electronic survey, which was sent via email to 800 addresses of actively working dentists in the Republic of Croatia. The survey was completed by 432 respondents.

RESULTS: $91.9 \%$ of participants considered dentistry a stressful occupation, $46.1 \%$ of respondents believed that practicing dentistry may cause problems in mental health, $93 \%$ of participants thought that practicing dentistry can endanger their general health. Regarding working experience, the participants' group with less than 10 years of experience identified fear of unsuccessful outcomes more frequently compared to their colleagues with more experience. Specialists perceived their health risks as lesser than expected. We found that $77.1 \%$ of participants were smokers.

Conclusions: Chronic stress remains one of the principal factors contributing to the decline in overall health and mental health among dental professionals. No association was found between gender and stress, or stressor perceptions. In regard to working experience, we found that younger dentists with up to 10 years of experience presented with more fear from unsuccessful outcomes. It was also found that general dentists perceived health risks as greater in contrast to specialists. Male participants reported a much greater frequency of consumption of alcoholic beverages than female counterparts. Also, specialists reported consuming strong alcoholic beverages more than expected.
\end{abstract}

KEY WORDS: stress, chronic stress, professional burnout, coping mechanisms, mental health.

J Stoma 2020; 73, 6: 326-333

DOI: https://doi.org/10.5114/jos.2020.102051

\section{INTRODUCTION}

\section{STRESS AND BURNOUT DEFINITIONS}

Stress is currently ubiquitous in the modern world and dentists are very susceptible to stress. In fact, dentistry is widely considered to be one of the most stressful of all health professions. Some studies suggest that dentists find their profession more stressful than other work, and that suicide, chemical addiction, burnout, and musculoskeletal problems may be the manifestations of this perception. Certain stressors can pose a serious threat to physical and mental well-being. One of the possible consequences of chronic work stress is occupational burnout [1].

\section{JOURNAL OF STOMATOLOGY CZASOPISMO STOMATOLOGICZNE

AdDRess for CORRespondence: Dr. Andrija Ban, Department of Paediatric Dentistry, University of Zagreb, School of Dental Medicine, 5 Gundulićeva St., Zagreb, HR-10000, Croatia, e-mail: aban@sfzg.hr

ReCEIVED: 02.11.2020 • ACCEPTED: 28.11.2020 • Published: 30.12.2020 
In dentistry, chronic work stress and burnout have been identified as potential dangers to professional and private life of dentists $[2,3]$. In most studies, burnout is measured using Maslach burnout inventory (MBI) [4], which recognizes three aspects of burnout, including emotional exhaustion (EE), depersonalization (D), and personal performance $(\mathrm{PA})$.

Burnout is defined as the syndrome of emotional exhaustion (EE) and cynicism that is common in people working with other people [4]. A systematic review by Amoafo et al. [5] examined significant factors associated with physicians' burnout. General medicine and dentistry are similar in terms of practice and patients' participation, and it is believed that dentists can experience a burnout due to many of the same factors.

\section{FACTORS CONTRIBUTING TO INCREASED STRESS}

Burnout seems to be associated with a shortfall in executive function or cognitive control [4], including working memory, planning, problem solving, and execution. Burnout by physicians and surgeons can affect the quality and safety of patient care, such as frequency of medical errors $[5,6]$, which are thought to be caused by effects on executive function.

A recent study [9] of primary care dentists found that an increased PA sensation, and EE and DP levels were associated with higher level of anxiety in clinical situations reported by themselves, suggesting that reduced burnout may lead to improved decision-making and therefore, patients' better outcomes.

Dentists are heavily affected by burnout syndrome (BOS), and factors such as time and organizational problems related to existing activity requirements as well as interpersonal roles and their ambiguity, create and/ or encourage, among other things, an emotional exhaustion [10].

It has been documented that a dental office is perceived as a health profession, which generates the most anxiety [11].

Various other health risks are associated with dealing with dentistry, such as chronic musculoskeletal problems [13], transmission of infectious diseases [14-16], or injuries that increase overall stress level.

TABLE 1. Respondents by gender

\begin{tabular}{|c|c|c|c|c|}
\hline & Frequency & Percent & $\begin{array}{l}\text { Valid } \\
\text { percent }\end{array}$ & $\begin{array}{c}\text { Cumulative } \\
\text { percent }\end{array}$ \\
\hline \multicolumn{5}{|l|}{ Valid } \\
\hline Male & 162 & 34.4 & 37.5 & 37.5 \\
\hline Female & 270 & 57.3 & 62.5 & 100.0 \\
\hline Total & 432 & 91.7 & 100.0 & \\
\hline $\begin{array}{l}\text { Missing } \\
\text { system }\end{array}$ & 39 & 8.3 & & \\
\hline Total & 471 & 100.0 & & \\
\hline
\end{tabular}

In a study by Pozos Radillo [12], no correlation was found between variables, including male gender, age, weight, height, number of children, marital status, socio-economic level, length of service, work with an assistant, daily working hours, etc., employment, family interaction time, and housework. The association of females with high chronic stress has been accepted [12]. Main causes of stress were identified as time pressure [17-19], fear of unforeseen results, fear of patient dissatisfaction, and financial problems [20-22].

\section{COPING MECHANISMS}

Various unhealthy stress management mechanisms have been observed, and their frequency in the dental population is also a problem. In recent years, there has been a growing importance of problems related to the use of alcohol and illegal drugs by dentists [29-34]. Drinking and consumption of drugs by dentists and doctors is of concern not only for their health and well-being, but also for the safety of the patients they care for. Normal coping mechanisms, such as physical exercise, are known to positively correlate with the reduction of stress and long-term health problems $[26,35]$.

A significant proportion of dentistry graduates have been shown to question their original career choices [36] because the field is demanding, and occupational diseases have a significant impact on health. Musculoskeletal disorders, vision, and skin problems are among the most commonly reported health problems [37]. Students enrolling in dental programs are relatively unaware of health-related hazards of the dental profession [38].

The aim of the study was to investigate the subjective perception of stress in dentists, confirm known correlations between stress and various factors, such as gender, age, socioeconomic level, work seniority, and specialization as well as to examine the influence of various coping mechanisms in its manifestation.

\section{MATERIAL AND METHODS}

The survey was taken by 432 respondents (female, 62.5\%; male, 37.5\%) (Table 1). The response rate among participants was $54 \%$. The research was conducted through an electronic survey, which was sent via email to 800 addresses of actively working dentists in the Republic of Croatia. Participation in the survey was anonymous and voluntary, and all respondents had been working as dental professionals for at least one year. The questionnaire consisted of two parts; the first part was demographics and included gender, age, length of service, and specialization. The second part was about the dentists' awareness of stress in dental profession. The study was approved by an ethics committee of the School of Dental Medicine in Zagreb.

The statistical analysis was performed with SPSS Statistics computer program as a combination of descrip- 


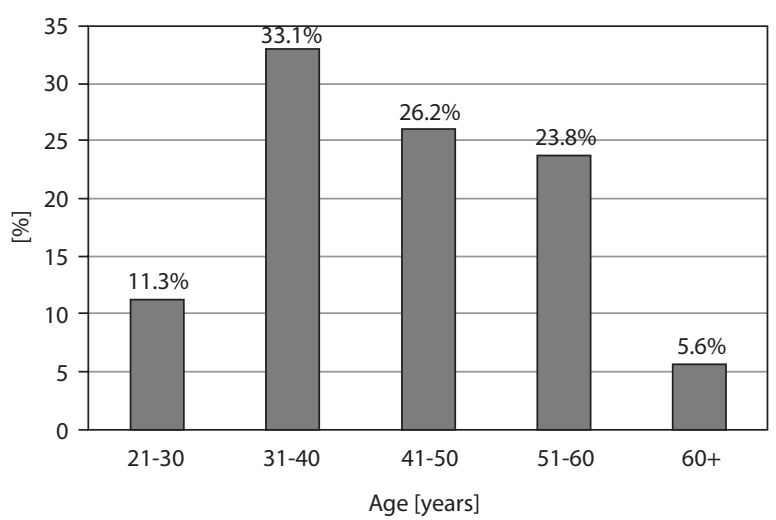

FIGURE 1. Respondents by age

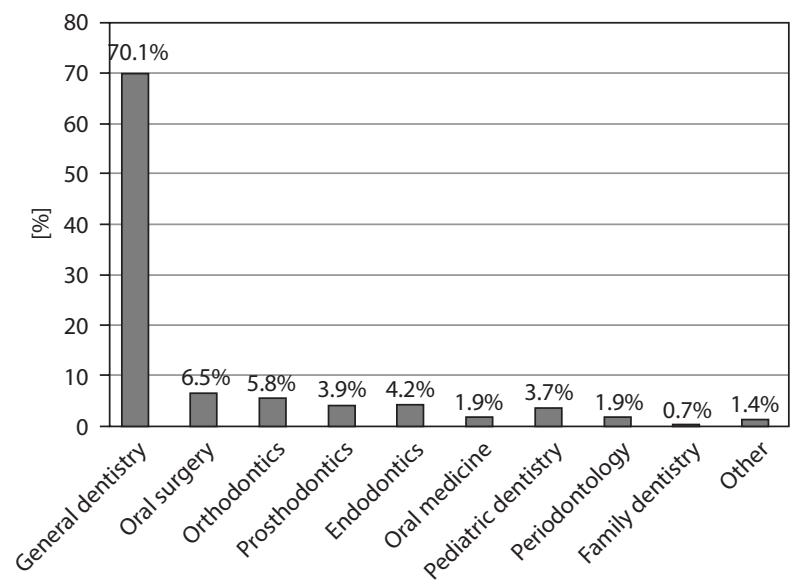

FIGURE 3. Respondents by specialization

tive and correlational analysis, with the relations being presented as non-parametric chi square analyses due to a reduced, nominal measurement.

\section{RESULTS}

The largest age group was between 31 and 40 years of age (33.1\%) (Figure 1). The greatest percentage of respondents (36.8\%) presented between 11 and 20 years of working experience (Figure 2). Most of the respondents were general dentists (70.1\%) (Figure 3).

\section{SUBJECTIVE PERCEPTION OF STRESS IN DENTISTS}

91.9\% of participants considered dentistry to be a stressful occupation, $4.7 \%$ did not consider stressful, while $3.4 \%$ of respondents were not sure (Figure 4). 46.1\% of participants believed that practicing dentistry may cause problems in mental health, 36.5\% considered that it cannot, and $17.4 \%$ of answers showed „not sure “. Furthermore, $93 \%$ of participants thought that practicing dentistry can endanger their general health, 5.5\% believed it cannot, and

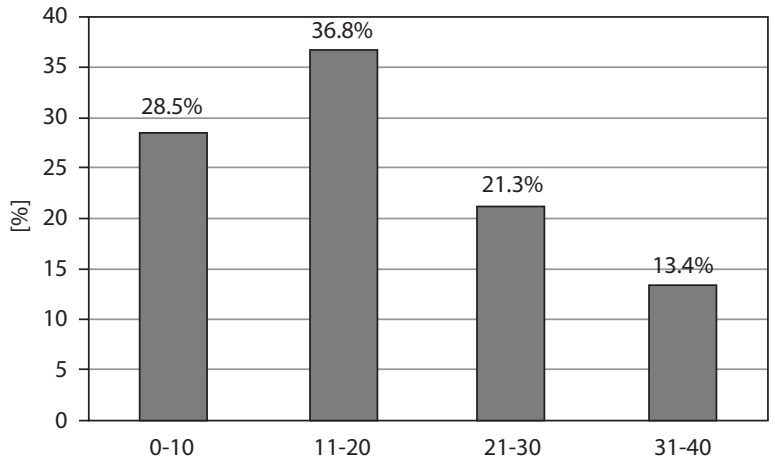

FIGURE 2. Years of working experience

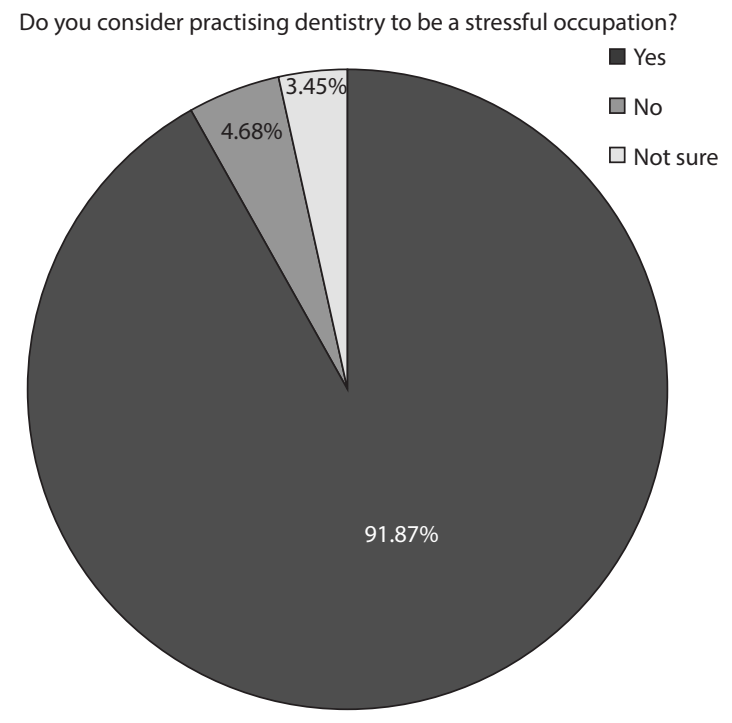

FIGURE 4. Subjective perception of stress in dentists

$1.4 \%$ of respondents were not sure. $89.6 \%$ of participants assumed they should pay greater attention to their health, $8 \%$ thought they should not, and $2.4 \%$ were not sure.

The greatest percentage of participants has identified time pressure as a significant source of stress (62.3\%). The fear of patient dissatisfaction was identified by $54.2 \%$ of participants. The fear of unsuccessful outcomes was recognized by $52.5 \%$ of respondents, while $39.1 \%$ identified financial problems and $6.7 \%$ chose „other" as their answer.

\section{STRESS AND GENDER CORRELATIONS}

The difference in subjective stress evaluation regarding participants' gender did not reveal a statistically significant difference $(\chi=0.620(2), p>0.05)$. The evaluation was consistent in both genders.

The difference in perceiving fear of unsuccessful outcomes as a source of stress, depending on gender did not show a statistically significant difference $(\chi=0.327$ (1), $p>0.05)$. 
TABLE 2. Years of experience* ${ }^{*}$ Fear of unsuccessful outcomes - crosstabulation

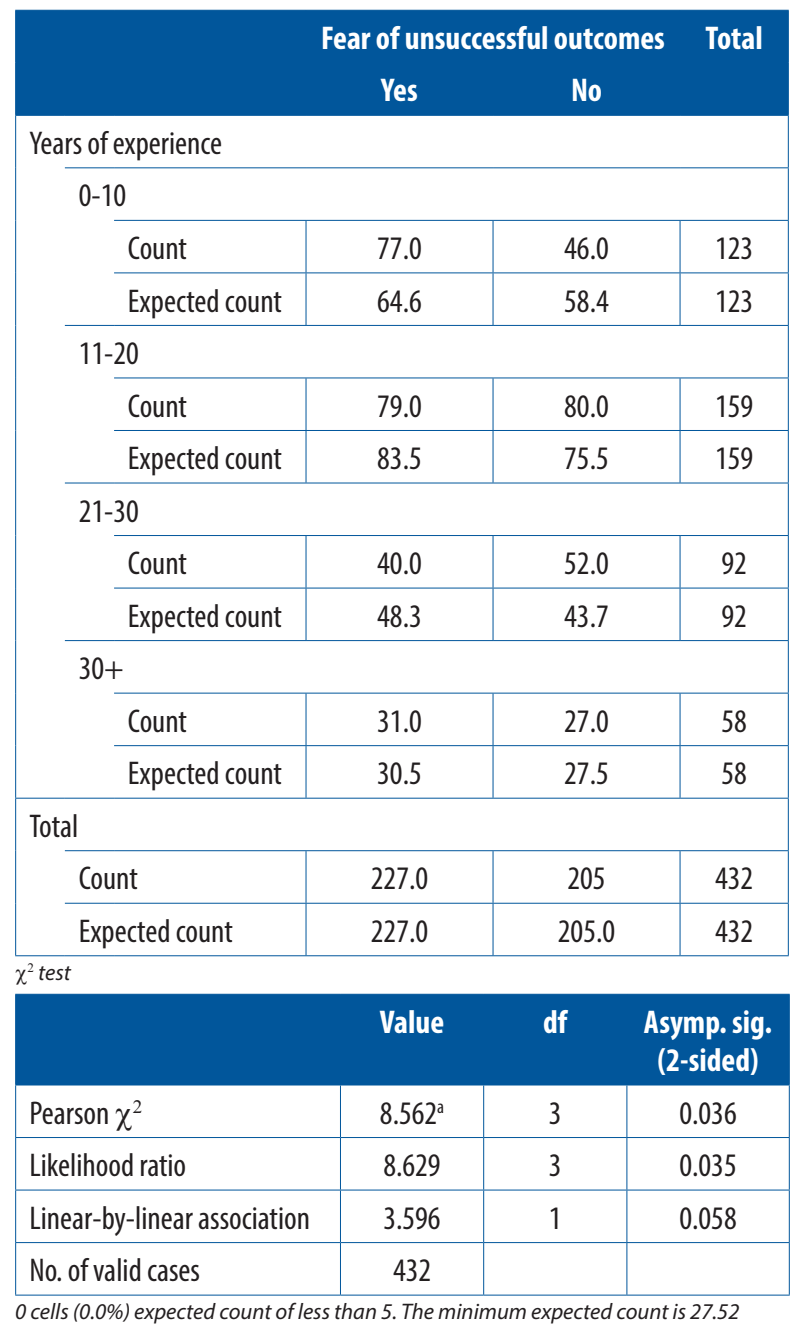

The difference in perceiving fear of patient dissatisfaction as a source of stress, depending on gender did not demonstrate a statistically significant difference $(\chi=0.022(1), p>0.05)$.

The difference in perceiving time pressure as a source of stress, depending on gender did not show a statistically significant difference $(\chi=1.577(1), p>0.05)$.

The difference in perceiving financial pressure as a source of stress, depending on gender did not demonstrate a statistically significant difference $(\chi=0.286(1), p>0.05)$.

\section{STRESS AND WORKING EXPERIENCE CORRELATIONS}

The difference in subjective perception of stress in dentist in relation to years of experience did not show a statistical significance $(\chi=7.669(6), p>0.05)$. Dentists with more or less years of experience equally perceived their profession as stressful.

The difference in fear of unsuccessful outcomes in relation to years of experience showed to be statistically significant $(\chi=8.552(3), p<0.05)$ (Table 2$)$. The partic- ipants' group of less than 10 years of experience identified fear of unsuccessful outcomes more frequently compared to the normal distribution, while the participants' group of 21-30 years of experience found this fear less frequently than the normal distribution.

The difference in perceiving fear of patient dissatisfaction as a source of stress, depending on years of working experience did not show a statistically significant difference $(\chi=5.219(3), p>0.05)$.

The difference in perceiving time pressure as a source of stress, depending on years of experience did not reveal a statistically significant difference $(\chi=3,929(3), p>0.05)$.

The difference in perceiving financial pressure as a source of stress, depending on years of experience did not show a statistically significant difference $(\chi=3.802(3), p>0.05)$.

The number of participants that in their own opinion should pay greater attention to their health in relation to years of working experience did not yield a statistically significant difference $(\chi=9.079(6), p>0.05)$.

\section{STRESS AND DENTAL SPECIALTY CORRELATIONS}

The difference in subjective perception of stress in specialists and general dentists was not statistically significant $(\chi=1.169(2), p>0.05)$.

The difference in subjective evaluation of health risks in specialists in relation to general dentists showed a statistically significant difference $(\chi=7.716(2), p<0.05)$ (Table 3). General dentists perceived health risks as greater than the expected normal distribution, while specialists perceived their health risks as lesser than expected.

The difference in alcohol consumption between specialists and general dentists demonstrated a statistically significant difference $(\chi=11.347(4), p<0.05)$ (Table 4). Specialists reported consuming strong alcoholic beverages more than expected compared to the normal distribution, while general dentists reported consuming less of strong alcohol.

However, it must be noted that most specialists in this survey were men, who also reported more alcohol consumption than women in this survey. The difference in frequency of consumption of strong alcoholic beverages between men and women was also statistically significant $(\chi=45.992(4), p<0.01)$.

\section{STRESS AND SUBSTANCES ABUSE AND/OR OTHER COPING MECHANISMS}

$77.1 \%$ of participants reported as smokers, while $22.9 \%$ denied smoking.

$42.1 \%$ of participants reported consumption of strong alcoholic beverages once a month, $38.7 \%$ stated no consumption at all, $13.1 \%$ reported their consumption as 1-2 times per week, while 5.4\% reported 3-4 times per week. The difference in stress perception in regard to reported consumption of strong alcoholic beverages did not show a statistically significant difference $(\chi=3.759(8), p>0.05)$. 
TABLE 3. Specialty* practicing dentistry can endanger my health - crosstabulation

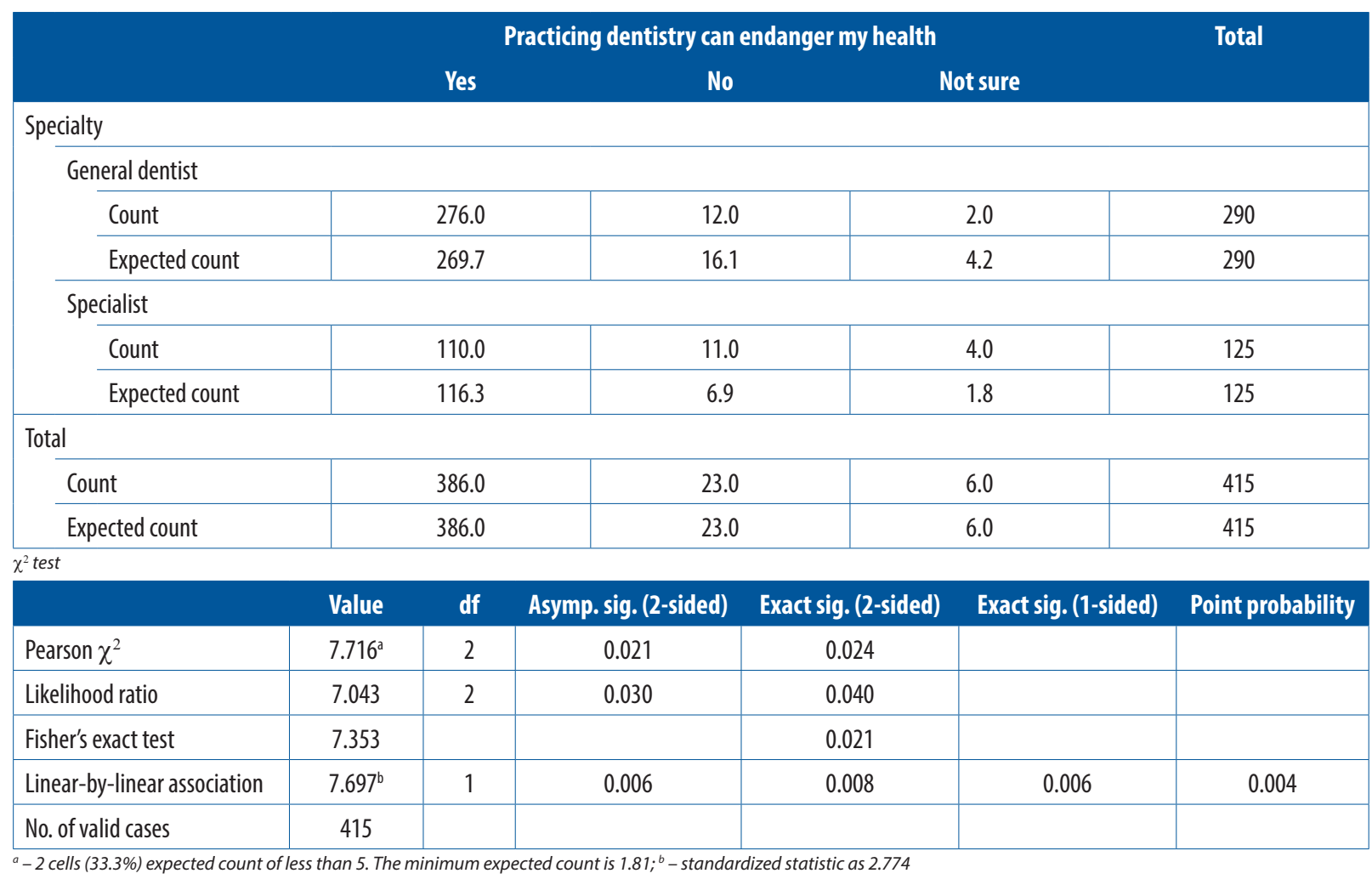

TABLE 4. Specialization*. How often do you consume strong alcoholic beverages? Crosstabulation

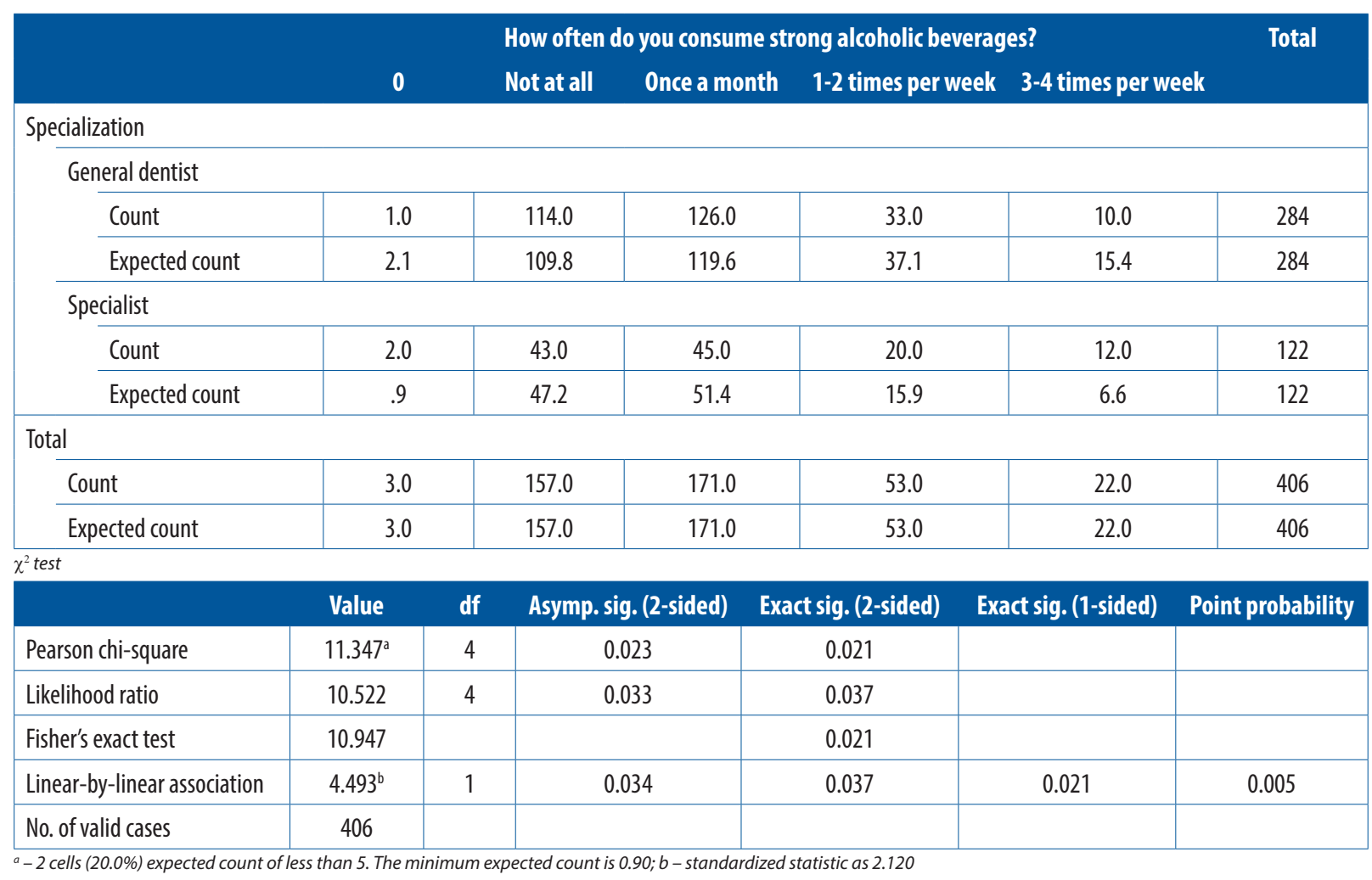

The difference in subjective stress perception between smokers and non-smokers did not reveal a statistically significant difference $(\chi=3.759(8), p>0.05)$.
The difference in frequency of consumption of strong alcoholic beverages in regard to gender was statistically significant $(\chi=45.992(4), p<0.01)$. Male participants 
TABLE 5. Participant gender*. How often do you consume alcoholic beverages? Crosstabulation

\begin{tabular}{|c|c|c|c|c|c|c|}
\hline & \multicolumn{5}{|c|}{ How often do you consume strong alcoholic beverages? } & \multirow[t]{2}{*}{ Total } \\
\hline & 0 & Not at all & Once a month & 1-2 per week & 3-4 per week & \\
\hline \multicolumn{7}{|l|}{ Gender } \\
\hline \multicolumn{7}{|l|}{ Male } \\
\hline Count & 3.0 & 33.0 & 77.0 & 30.0 & 16.0 & 159 \\
\hline Expected count & 1.2 & 61.5 & 67.0 & 20.8 & 8.6 & 159 \\
\hline \multicolumn{7}{|l|}{ Female } \\
\hline Count & 0.0 & 124.0 & 94.0 & 23.0 & 6.0 & 247 \\
\hline Expected count & 1.8 & 95.5 & 104.0 & 32.2 & 13.4 & 247 \\
\hline \multicolumn{7}{|l|}{ Total } \\
\hline Count & 3.0 & 157.0 & 171.0 & 53.0 & 22.0 & 406 \\
\hline Expected count & 3.0 & 157.0 & 171.0 & 53.0 & 22.0 & 406 \\
\hline
\end{tabular}

\begin{tabular}{|c|c|c|c|c|c|c|}
\hline & Value & df & Asymp.sig. (2-sided) & Exact sig. (2-sided) & Exact sig. (1-sided) & Point probability \\
\hline Pearson $\chi^{2}$ & $1.227^{\mathrm{a}}$ & 1 & 0.268 & 0.278 & 0.162 & \\
\hline Continuity correction ${ }^{b}$ & 0.974 & 1 & 0.324 & & & \\
\hline Likelihood ratio & 1.216 & 1 & 0.270 & 0.278 & 0.162 & \\
\hline Fisher's exact test & & & & 0.278 & 0.162 & \\
\hline Linear-by-linear association & $1.224^{c}$ & 1 & 0.269 & 0.278 & 0.162 & 0.052 \\
\hline No. of valid cases & 406 & & & & & \\
\hline
\end{tabular}

${ }^{a}-0$ cells $(0.0 \%)$ expected count of less than 5 . The minimum expected count is $36.42 ;^{b}-$ computed only for $a 2 \times 2$ table ${ }^{c}-$ standardized statistic as 1.106

reported a much greater frequency of consumption than female participants (Table 5).

\section{STRESS AND ENGAGEMENT IN SPORTS ACTIVITIES CORRELATIONS}

The greatest percentage of respondents was engaged in sports activities 1-2 times per week (42\%), while $33.3 \%$ did not engage themself in sports at all. $19.7 \%$ of participants participated in sports activities 3-4 times per week and $5 \%$ was engaged every day. The largest percentage of respondents traveled by a car (63.7\%), while $25.6 \%$ walked to work, $6.7 \%$ used a public transport, $2.7 \%$ traveled by a bicycle, and $1.2 \%$ by a motorcycle. The difference in subjective stress perception in relation to the frequency of engaging in sports did not show as statistically significant. ( $\chi=10.727(6), p>0.05)$. The difference in subjective stress perception in relation to the mode of transport to work did not demonstrate as statistically significant $(\chi=10.727(6), p>0.05)$.

\section{DISCUSSION}

\section{GENERAL PERCEPTIONS}

When measuring the subjective perception of stress in dental professionals, our results showed that $91.9 \%$ of participants considered dentistry a stressful occupation, while $4.7 \%$ did not consider. This perception is in line with the existing conclusions about dentistry being thought as one of the most stressful of all healthcare professions [1, 10, 11]. Furthermore, $46.1 \%$ of respondents believed that practicing dentistry may cause problems in mental health. This is also in line with existing research that recognizes professional burnout as one of the possible consequences of chronic professional stress $[1-6,9,10]$.

We found that $93 \%$ of participants thought that practicing dentistry could endanger their general health, showing that a greater proportion of dentists are concerned about their general health, rather than mental health, in terms of professional risks. Indeed, there are significant health risk factors associated with dentistry, ranging from chronic disease risks to acute states or infection risks [13-16]. Following this, we also found that $89.6 \%$ of participants believed they should pay greater attention to their health.

\section{STRESS FACTORS PERCEPTION}

In this survey, the participants identified time pressure as the greatest stress factor $(62.3 \%)$, followed by patient dissatisfaction (54.2\%), and the fear of unsuccessful outcomes was identified by $52.5 \%$ of respondents. In another study by Myers, time pressure was also identified as the greatest stress factor in $64.4 \%$ of participants [17]. 


\section{CORRELATIONS WITH EXTERNAL FACTORS}

We found that the difference in subjective stress evaluation in regard to participant gender did not show a statistically significant difference. The opposite has been shown by a research by Pozos Radillo, where an association of the female gender with high level of chronic stress was accepted [12]. Furthermore, we tested various correlations and found that the difference in perceiving fear of unsuccessful outcomes as a source of stress, depending on gender did not prove to be a statistically significant difference. There was also no difference in perceiving fear of patient dissatisfaction, time pressure, or financial pressure as sources of stress, depending on gender.

In regards to working experience, we found that dentists with more or less years of experience equally perceived their profession as stressful, however, the participants' group of less than 10 years of experience identified fear of unsuccessful outcomes more frequently compared to their colleagues with more experience, which is in line with existing conclusions about stress amongst young dentists and dental students [3, 23]. In some papers, there was no such correlation [12]. Furthermore, there was no significant difference in the perception of other tested stressors (fear of patient dissatisfaction, time pressure, or financial pressure) regarding working experience.

Considering dental specialization, we found that the difference in subjective perception of stress in specialists and general dentists was not statistically significant, however, it was found that general dentists perceived health risks as greater than the expected normal distribution, while specialists perceived their health risks as lesser than expected.

\section{COPING MECHANISMS}

The connection between stress and substance abuse was also investigated. In this survey, we found that $77.1 \%$ of participants reported as smokers, while $22.9 \%$ denied smoking, and $42.1 \%$ of respondents reported consumption of strong alcoholic beverages once a month, $38.7 \%$ stated no consumption at all, $13.1 \%$ reported consumption as 1-2 times per week, while 5.4\% stated 3-4 times per week. There was no significant difference in stress perception in terms of reported consumption of strong alcoholic beverages, nor between smokers and non-smokers. Various research found that substance dependency is not prevalent among dentists than in the general population [24], while in some cases, it has been proven that smoking is more prevalent in comparison to the general population [25].

The difference in frequency of consumption of strong alcoholic beverages in gender was statistically significant. The male participants reported a much greater frequency of consumption than female participants. Also, specialists reported consuming strong alcoholic beverages more than expected compared to the normal distribution, while general dentists reported consuming less. However, it must be noted that most specialists in this survey were men, who reported more alcohol consumption.

The greatest percentage of respondents were engaged in sports activities 1-2 times per week (42\%), while $33.3 \%$ were not involved in sports at all. 19.7\% of participants engaged in sports activities 3-4 times per week, and 5\% were engaged every day. The difference in subjective stress perception in relation to the frequency of engaging in sports or walking to work has not been shown to be statistically significant. However, in other papers, a direct link has been established between engaging in everyday sports activities and a reduction in musculoskeletal chronic problems $[26,27]$.

\section{CONCLUSIONS}

Chronic stress stands as one of the main factors contributing to the decline in overall health and mental health in dental professionals. Most of the participants in our research reported feeling stressed, and identified major stressors in their workplace, which is in line with existing research on the subject. These were primarily time pressure, patient dissatisfaction, and fear of unsuccessful outcomes. Most participants believed they should pay more attention to their health, and prevent its deterioration.

No association was found between gender and stress or stressor perceptions. Regarding working experience, we found that younger dentists with up to 10 years of experience presented more fear from unsuccessful outcomes. It was also found that general dentists perceived health risks as greater in contrast to specialists.

There was no significant difference in stress perception regarding reported consumption of strong alcoholic beverages, nor between smokers and non-smokers. However, $77.1 \%$ of participants were smokers, which is significantly above the national average (33\%) [28]. The male participants reported a much greater frequency of consumption than female participants. Also, specialists revealed consuming strong alcoholic beverages more than expected.

The difference in subjective stress perception in relation to the frequency of engaging in sports or walking to work did not prove to be significant.

The conclusions here can be used to further confirm the correlations between chronic stress and negative longterm health outcomes, such as BOS and professional outcomes. Also, the investigated associations may be further analyzed to assess the relation between various factors, such as gender, age, weight, height, number of children, marital status, socioeconomic level, work seniority, working with an assistant, hours worked daily, other employment, substance abuse, sports etc., and chronic stress. Furthermore, it can be used to validate future surveys and improve measurement parameters in relevant correlations. 


\section{CONFLICT OF INTEREST}

The authors declare no potential conflicts of interest with respect to the research, authorship, and/or publication of this article.

\section{References}

1. Gangwar A, Kiran U. Occupational stress among dentists. Int J Sci Res 2016; 4: 28-30.

2. Humphris G. A review of burnout in dentists. Dent Update 1998; 25: 392-396.

3. Rada RE, Johnson-Leong C. Stress, burnout, anxiety and depression among dentists. J Am Dent Assoc 2004; 135: 788-794.

4. Maslach C, Jackson SE, Leiter MP. MBI manual, $3^{\text {rd }}$ ed.

5. Amoafo E, Hanbali N, Patel A, Singh P. What are the significant factors associated with burnout in doctors? Occup Med (Lond) 2014; 2: 117-121.

6. Deligkaris P, Panagopoulou E, Montgomery AJ, Masoura E. Job burnout and cognitive functioning: a systematic review. Work \& Stress 2014; 28: 107-123.

7. Shanafelt TD. Burnout and medical errors among American surgeons. Ann Surg 2010; 251: 995-1000.

8. West CP. Association of perceived medical errors with resident distress and empathy. JAMA 2006; 296: 10711078.

9. Chipchase SY, Chapman HR, Bretherton R. A study to explore if dentists' anxiety affects their clinical decision-making. Br Dent J 2017; 222: 277-290.

10. Díaz R, Pérez E, Lartigue M. Desgaste profesional en un grupo de odontólogos. Rev ADM 2006; 63: 220-224.

11. Visoso A, Sánchez P, Montiel N. Síndrome de Burnout en la Facultad de Odontología de la Universidad Autónoma del Estado de México: un Estudio Comparativo. Int J Odontostomat 2012; 6: 129-138.

12. Pozos Radillo BE, Tórrez López TM, Aguilera Velasco MDLÁ, et al. Stress-associated factors in Mexican dentists. Braz Oral Res 2008; 22: 223-228.

13. Tomaszuk A, Tomaszuk J, Wilczyńska-Borawska M. Dangers and risks associated with the practice of the dentist. J Public Health Nurs Med Rescue 2018; 259: 1-5.

14. Zuckerman AJ. Occupational exposure to hepatitis B virus and human immunodeficiency virus: a comparative risk analysis. Am J Infect Control 1995; 23: 286-289.

15. Robinson Jr EN, De Bliek R. The college student, the dentist, and the North Carolina senator: risk analysis and risk management of HIV transmission from health care worker to patient. Med Decis Making 1996; 16: 86-91.

16. Sepkowitz KA. Occupationally acquired infections in health care workers: part II. Ann Intern Med 1996; 125: 917-928.

17. Myers HL, Myers LB. 'It's difficult being a dentist': stress and health in the general dental practitioner. Br Dent J 2004; 197: 89-93.

18. Diederich A. MDFT account of decision making under time pressure. Psychon Bull Rev 2003; 10: 157-166.

19. Howard JH, Cunningham DA, Rechnitzer PA, Goode RC. Stress in the job and career of a dentist. J Am Dent Assoc 1976; 93: 630-636.

20. Sondell K, Söderfeldt B, Palmqvist S. Dentist-patient communication and patient satisfaction in prosthetic dentistry. Int $J$ Prosthodont 2002; 15: 28-37.

21. Corah NL, O'Shea RM, Pace LF, Seyrek SK. Development of a patient measure of satisfaction with the dentist: the Dental Visit Satisfaction Scale. J Behav Med 1984; 7: 367-373.

22. Corah NL. Dental anxiety. Assessment, reduction and increasing patient satisfaction. Dent Clin N Am 1988; 32: 779-790.

23. Pérez F. Vocational satisfaction, coping strategies, and perceived stress as factors of 'burnout'in clinical dental students. J Oral Res 2013; 2: 131-134.
24. Kenna GA, Wood MD. The prevalence of alcohol, cigarette and illicit drug use and problems among dentists. J Am Dent Assoc 2005; 136: 1023-1032.

25. Rodrigues GA, Galvão V, Viegas CADA. Prevalence of smoking among dentists in the Federal District of Brasília, Brazil. J Bras Pneumol 2008; 34: 288-293.

26. Koneru S, Tanikonda R. Role of yoga and physical activity in work-related musculoskeletal disorders among dentists. J Int Soc Prev Community Dent 2015; 5: 199-204.

27. Biglar A, Farzaneh H. The investigation of relationship between work-related musculoskeletal disorders and level of physical activity and body posture of dentists in Mashhad city in 2012-2013. J Res Med Sci 2015; 2: 37-31.

28. Padjen I, Dabić M, Glivetić T, Biloglav Z, Biočina-Lukenda D, Lukenda J. The analysis of tobacco consumption in Croatia - are we successfully facing the epidemic? Cent Eur J Publ Heal 2012; 20: 5-10.

29. Busch L. Rehabilitating the impaired dentist: a look at what the profession is doing to help. J Am Dental Assoc 1982; 105: 781-787.

30. Giangrego E, Oberg S. Chemical dependency: the road to recovery. J Am Dental Assoc 1987; 115: 17-27.

31. Peterson RL, Avery JK. The alcohol-impaired dentist: an educational challenge. J Am Dental Assoc 1988; 117: 743-748.

32. Anon. Sick dentists - an escalating problem. Br Dent J 1991; 171: 151.

33. Anon. Drink, drugs and dentistry — are you at risk? Br Dent J 1996;180:392-393.

34. Newbury-Birch D, Lowry RJ, Kamali F. The changing patterns of drinking, illicit drug use, stress, anxiety and depression in dental students in a UK dental school: a longitudinal study. Br Dent J 2002; 192: 646-649.

35. Hansmann R, Eigenheer-Hug SM, Berset E, Seeland K. Erholungseffekte sportlicher Aktivitäten in stadtnahen Wäldern, Parks und Fitnessstudios| Restorative effects of sports activities in suburban forests, parks, and fitness centres. Schweiz Z F Forstw 2010; 161: 81-89.

36. Kobale M, Klaić M, Bavrka G, Vodanović M. Motivacija za upis na studij i percepcija o karijeri među studentima Stomatološkog fakulteta Sveučilišta u Zagrebu. Acta Stomatol Croat 2016; 50: 207-214.

37. Vodanović M, Sović S, Galić I. Profesionalni zdravstveni problemi među stomatolozima u Hrvatskoj. Acta Stomatol Croat 2016; 50 : 310-320.

38. Matoš K, Jurec Z, Galić I, Vodanović M. Izobrazba o profesionalnim bolestima i zdravstvenim navikama među studentima dentalne medicine u Hrvatskoj. Acta Stomatol Croat 2016; 50: 49-57. 